\title{
Newly graduated nurses' orientation experiences: A systematic review of qualitative studies
}

\author{
Abstract \\ Objective: This systematic review describes the experiences of the orientation into nursing of newly \\ graduated nurses. \\ Design: Systematic review. \\ Methods: Data was collected from five databases: Medic, EBSCO Cinahl, Scopus, PsycARTICLES \\ and ERIC (ProQuest). Qualitative, peer reviewed, original studies published in English, Swedish or \\ Finnish before February 2016 and exploring newly graduated nurses' experiences of the nursing \\ orientation process were included. The studies were selected by screening titles, abstracts and full \\ texts and the quality of the studies was assessed by two researchers independently. Data was \\ analysed using content analysis. \\ Results: Thirteen studies were chosen for the review. Newly graduated nurses' orientation \\ experiences were divided into four main categories: experiences related to orientation \\ arrangements; experiences related to the preceptor; experiencing role transition during the \\ orientation and suggestions for changes based on orientation experiences. The findings establish \\ that the orientation and the preceptor have a great impact on how newly graduated nurses \\ experience the start of their career. Often, newly graduated nurses wish to continue their \\ relationship with their preceptor after the orientation period. \\ Conclusions: Results bring together both the positive and negative aspects that newly graduated \\ nurses relate as regards their current orientation programmes. Attention needs to be paid to the \\ variation and imbalance in the quality of orientation programmes and preceptors. A more formal \\ form of mentorship needs to be developed further.
}

\section{Keywords}

New graduate, Nurses, Preceptorship, Systematic review

\section{Introduction}

Nurses exiting the nursing profession have raised concerns internationally. The European Commission has estimated that in 2020, there will be a shortfall of 970,000 employees in healthcare and 590,000 of those will be nurses (Sermeus and Bruyneel, 2010). The intention to exit nursing is most common among young, newly graduated nurses (Goh et al., 2015; Rudman et al., 2010; Salminen, 2012). According to studies, 36\% of 24-29-year-old nurses (Flinkman et al., 2008) and $37 \%$ of under 35-year-old nurses (Salminen, 2012) had thought about exiting nursing at least once in a month.

Exiting nursing has been noticed to be connected to dissatisfaction with the orientation (Flinkman et al., 2013; Laschinger, 2012) and to follow simultaneous changes that are happening in levels of depression symptoms (Rudman and Gustavsson, 2011) and burnout (Rudman and Gustavsson, 2011; Rudman et al., 2014). Almost every fifth newly graduated nurse reported having very high burnout levels and among other things, the feeling of being poorly prepared for nursing is a sign of developing burnout (Rudman and Gustavsson, 2011). In this review, newly graduated nurses include those who have less than three years' experience in professional nursing as a nurse. The first three years of working at the same job or doing similar tasks is important for growing as a competent nurse (Benner, 1984). Newly graduated nurses need more support for competence development (Lofmark et al., 2006; Yeh and Yu, 2009) as well as wellbeing at work (Tastan et al., 
2013; Yeh and Yu, 2009), because they suffer from fatigue, feel dissatisfaction (Missen et al., 2014; Tastan et al., 2013) and have greater stress (Yeh and Yu, 2009).

Orientation is one way to improve newly graduated nurses' wellbeing (Park and Jones, 2010), selfassurance, competence (Scott et al., 2008) and satisfaction with the profession (Scott et al., 2008; Tastan et al., 2013), and therefore also turnover rates (Missen et al., 2014). Orientation is defined as the activity where someone is familiarised with something (Oxford Dictionary of English, 2016) and the purpose of the orientation is to ease the transition process from student to qualified nurse, increasing both competence and commitment (Beecroft et al., 2001). In this review, the orientation of newly graduated nurses was understood as an aid for newly graduated nurses to become assured providers of good and safe patient care. The duration, structure and content of orientations vary between workplaces (Rush et al., 2013; Scott et al., 2008). Many newly graduated nurses have the opportunity to be preceptored during their orientation, but this is not the case in all workplaces (Rush et al., 2015). Preceptor is a term used for staff members who work as role models for newly graduated nurses and facilitates the transition process by giving guidance and helping with prioritizing (Myrick and Yonge, 2002). Preceptorship is often confused with the term mentorship. The principal difference between these terms is, that preceptorship is a short-term process during the orientation, whereas mentorship is a longer-term process during the whole work career. Preceptorship is for new staff members while mentorship is for all staff members. (Firtko et al., 2005.) Some organisations offer rotations in different clinical areas or wards during the orientation. (Malouf and West, 2011).

Newly graduated nurses' orientation has been recognised as an important area in wellbeing at work and development as a competent nurse. There are systematic reviews of newly graduated nurses' experiences and expectations related to the transition from student to newly qualified nurse (Higgins et al., 2010; Whitehead and Holmes, 2011) as well as the connection between orientation programmes and newly graduated nurses' job satisfaction (Lin et al., 2014), orientation programmes' impact on newly graduated nurses' clinical decision-making and leadership skills (AL-Dossary et al., 2014).

A broader perspective is needed to gain a deeper understanding of how newly graduated nurses have experienced the orientation so as to develop the orientation based on newly graduated nurses' needs. As far as we know, there is no systematic review of qualitative studies concerning newly graduated nurses' experiences of orientation. Therefore, the aim of this review was to describe the newly graduated nurses' experiences of the orientation in nursing. The research question was: What kind of orientation experiences do newly graduated nurses have in nursing?

\section{Methods}

\section{Search strategy}

This systematic review of qualitative studies was conducted according to guidelines from the Centre for Reviews and Dissemination (CRD, 2009) and Joanna Briggs Institute User guide (JBI, 2014). Data was collected from five databases: Medic, EBSCO Cinahl, Scopus, PsycARTICLES and ERIC (ProQuest) in February 2016. No limit for publication year was set. Searches from PsycARTICLES and ERIC were combined so that results from both databases were obtained with one search. Search strategies, terms and limitations (Table 1) were selected with the aid of an information specialist.

A total of 513 studies were found from the different electronic databases used as follows: Medic $(n=2)$, from EBSCO Cinahl $(n=260)$, Scopus $(n=247)$, PsycARTICLES and ERIC (ProQuest) 
$(n=4)$. To handle search results, the reference management programme RefWorks was used (Higgins and Green, 2011). First, duplicates $(n=131)$ were removed to reduce publication bias (CRD, 2009).

Table 1. Search strategy, terms and limitations.

\begin{tabular}{|c|c|c|}
\hline Database & Search terms & Limitation \\
\hline Medic & Perehdyt* & Original study \\
\hline \multirow{7}{*}{ EBSCO Cinahl } & MH "New Graduate Nurses" & \multirow[t]{7}{*}{ Peer reviewed } \\
\hline & AND & \\
\hline & orientat* OR preceptor* OR mentor* OR internshi* OR MH & \\
\hline & "Preceptorship" OR MH ”Employee Orientation" OR MH & \\
\hline & "Internship and Residency" OR MH ”Mentorship" & \\
\hline & AND & \\
\hline & experienc* OR feel* & \\
\hline \multirow{7}{*}{ Scopus } & "new* qualifi*" OR "new* graduate*" & \\
\hline & AND & \\
\hline & nurs* & \\
\hline & AND & \\
\hline & orientat* OR preceptor* OR mentor* OR internshi* & \\
\hline & AND & \\
\hline & experienc* OR feel* & \\
\hline \multirow{6}{*}{ PsycARTICLES } & "newly qualifi*" OR "new qualifi*" OR "newly graduate*" & \multirow[t]{7}{*}{ Peer reviewed } \\
\hline & OR "new graduate*" & \\
\hline & AND & \\
\hline & nurs* & \\
\hline & AND & \\
\hline & orientat* OR preceptor* OR internshi* OR mentor* & \\
\hline ERIC (ProQuest) & $\begin{array}{l}\text { AND } \\
\text { experienc* OR feel* }\end{array}$ & \\
\hline
\end{tabular}

\section{Study selection}

382 studies were included in a three step study selection process. In the study selection phase, the relevant studies were selected by first screening titles $(n=382)$ and then abstracts $(n=284)$ and at the end full texts $(n=62)$ by two researchers $(K P, M K)$ independently. Disagreement between researchers regarding eligibility was resolved through discussion.

All the studies had to meet the following criteria adopted from the PICoS (CRD, 2009) for inclusion in this review: $\mathrm{P}=$ participants, $\mathrm{I}=$ phenomena of interest, $\mathrm{Co}=$ context and $\mathrm{S}=$ types of studies (Table 2). One study in unfamiliar languages (other than English, Finnish, or Swedish) was removed in screening the full texts. The study selection process is shown in Figure 1.

Table 2. Inclusion and exclusion criteria of the study selection.

\begin{tabular}{ll}
\hline Inclusion criteria & Exclusion criteria \\
\hline $\begin{array}{l}\text { Participants: newly graduated nurses (<3 years working } \\
\text { experience) }\end{array}$ & $\begin{array}{l}\text { Participants: students, not newly graduated nurses ( }>3 \\
\text { years working experience) or preceptors }\end{array}$ \\
& $\begin{array}{l}\text { Phenomenon of interest: Study does not handle } \\
\text { experiences of orientation at all, }\end{array}$ \\
Phenomenon of interest: the experiences of orientation & $\begin{array}{l}\text { Nurses' results of experiences in orientation have not } \\
\text { been described separately from the other participants' } \\
\text { results } \\
\text { Context: all nursing contexts }\end{array}$ \\
$\begin{array}{l}\text { Type of study: a quantitative study, } \\
\text { not an original study, published in other languages than }\end{array}$ \\
$\begin{array}{l}\text { peer reviewed, original study, published in English, } \\
\text { in English, Swedish or Finnish }\end{array}$ \\
\hline
\end{tabular}




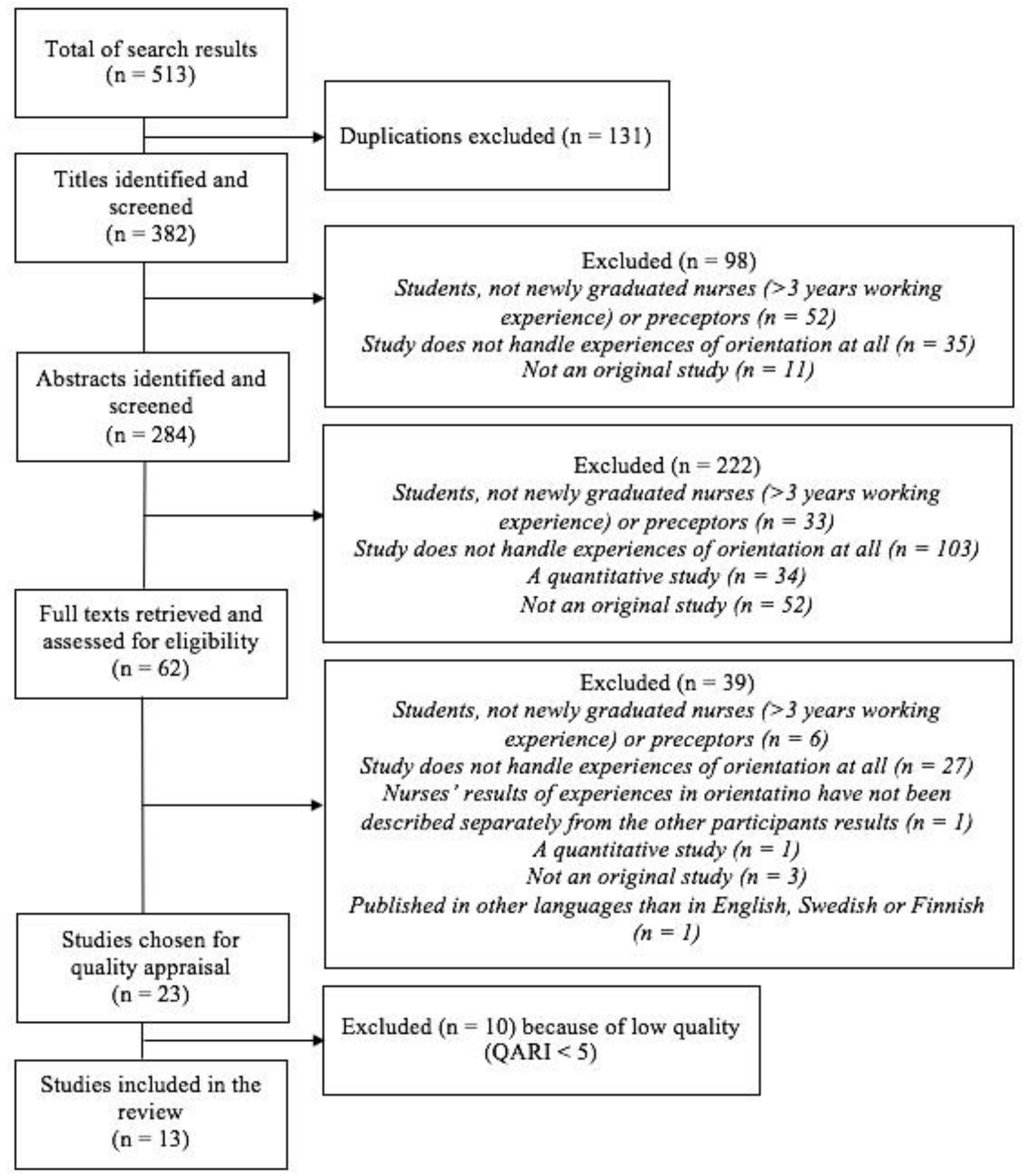

Figure 1. Study selection process of the original studies adapted from CRD (2009).

\section{Quality appraisal}

To ascertain the quality of the studies chosen for the review and to increase the reliability of the review, a critical appraisal was conducted for the studies $(n=23)$ chosen based on full texts by two researchers (KP, MK) (CRD, 2009). For assessing the quality of studies, the Joanna Briggs Institute's (JBI) Qualitative Assessment and Review Instrument (QARI) with ten criteria was used. To be selected for this review, original studies had to fulfil at least five assessment criteria. Quality was quantified by calculating scores of either 0 or 1 point per criterion. The quality scores of the 
studies varied from two to ten. Based on the quality appraisal, 13 studies were included in this review. Quality scores of the studies chosen to the review are presented in Table 3.

\section{Data extraction and analysis}

Processing of the research material started with the extraction of the data (CRD, 2009). Data extraction table (Table 3) was formed by following Higgins and Green's (2011) and the Centre for Review and Dissemination's (2009) instructions. Data was analysed using content analysis, which is a way to analyse different kinds of literature or collected data systematically and objectively. Content analysis can be inductive or deductive depending on the aim of the study. (Elo and Kyngäs, 2008.) In this review, inductive content analysis was used. By following the research question, researchers defined the unit of the analysis, which was either some words or a sentence. Thereafter, the data was coded, grouped and categorised, and the abstraction process was conducted. (Elo and Kyngäs, 2008.) The analysis was conducted by one researcher (KP) and verified by the other researcher (MK). 
Table 3. Extracted data from the studies selected to the review.

\begin{tabular}{|c|c|c|c|c|c|c|}
\hline $\begin{array}{l}\text { Authors and } \\
\text { country }\end{array}$ & Purpose & Participants & Orientation & $\begin{array}{l}\text { Methodology: data } \\
\text { collection and } \\
\text { analysis }\end{array}$ & Key findings & $\begin{array}{l}\text { Quality } \\
\text { assessment }\end{array}$ \\
\hline $\begin{array}{l}\text { Al Awaisi et } \\
\text { al., 2015, } \\
\text { Oman }\end{array}$ & $\begin{array}{l}\text { To explore the } \\
\text { experiences of new } \\
\text { graduate nurses during } \\
\text { their transition period in } \\
\text { the Sultanate of Oman }\end{array}$ & $\begin{array}{l}15 \text { new graduate } \\
\text { nurses (<1 year } \\
\text { from } \\
\text { graduation), } \\
8 \text { student nurses, } \\
5 \text { preceptors, } \\
5 \text { clinical } \\
\text { instructors, } \\
5 \text { head nurses, } \\
4 \text { managers }\end{array}$ & $\begin{array}{l}\text { 6-month internship } \\
\text { programme with } \\
\text { rotation in different } \\
\text { wards as well as } \\
\text { abroad and 1-month } \\
\text { orientation in the } \\
\text { ward where the new } \\
\text { graduate nurse was } \\
\text { going to work }\end{array}$ & $\begin{array}{l}\text { Case study } \\
\text { methodology } \\
\text { Semi-structured } \\
\text { individual and focus } \\
\text { group interviews, } \\
\text { observation and } \\
\text { documentary } \\
\text { analysis } \\
\text { Thematical analysis }\end{array}$ & $\begin{array}{l}\text { New graduates thought } \\
\text { the internship programme } \\
\text { was an important period } \\
\text { in role transition. It gave } \\
\text { them opportunity to learn } \\
\text { needed competencies in } \\
\text { the working environment. } \\
\text { Little by little, new } \\
\text { graduates got to take more } \\
\text { responsibility for patients. } \\
\text { Many new graduates } \\
\text { valued preceptors as } \\
\text { remarkable teachers. } \\
\text { However, some saw } \\
\text { preceptors as not prepared } \\
\text { for role modelling, } \\
\text { preceptors teaching wrong } \\
\text { practices and experienced } \\
\text { lack of time in teaching. }\end{array}$ & 9 QARI \\
\hline $\begin{array}{l}\text { Delaney, 2003, } \\
\text { USA }\end{array}$ & $\begin{array}{l}\text { To examine and describe } \\
\text { graduate nurses' } \\
\text { orientation experiences }\end{array}$ & $\begin{array}{l}10 \text { graduate } \\
\text { nurses }\end{array}$ & $\begin{array}{l}\text { hospital's caring- } \\
\text { based orientation, } \\
12 \text { weeks }\end{array}$ & $\begin{array}{l}\text { Phenomenological } \\
\text { method } \\
\text { Interviews } \\
\text { Analysed using } \\
\text { Colaizzi's method }\end{array}$ & $\begin{array}{l}\text { Most graduates thought } \\
\text { the } 12 \text {-week orientation } \\
\text { program was enough, and } \\
\text { helped them increase } \\
\text { confidence and feel } \\
\text { connection to the working } \\
\text { unit. Especially when } \\
\text { preceptors were } \\
\text { experienced, they were } \\
\text { seen having a positive } \\
\text { effect during the transition }\end{array}$ & 10 QARI \\
\hline
\end{tabular}




\begin{tabular}{|c|c|c|c|c|}
\hline $\begin{array}{l}\text { Evans et al., } \\
2008, \\
\text { Australia }\end{array}$ & $\begin{array}{l}\text { To determine the } \\
\text { strengths and weaknesses } \\
\text { of transition support } \\
\text { programs for newly } \\
\text { registered nurses }\end{array}$ & $\begin{array}{l}9 \text { new graduate } \\
\text { nurses } \\
\text { (completed } \\
\text { transition } \\
\text { support } \\
\text { programme } \\
\text { within } 12 \\
\text { months), } \\
13 \text { experienced } \\
\text { nurses }\end{array}$ & $\begin{array}{l}\text { 12-month transition } \\
\text { support programme } \\
\text { with 3-4 rotations in } \\
\text { different clinical } \\
\text { areas, programmed } \\
\text { study days and staff } \\
\text { support }\end{array}$ & $\begin{array}{l}\text { Descriptive design } \\
\text { Semi-structured } \\
\text { interviews } \\
\text { Theme extraction }\end{array}$ \\
\hline
\end{tabular}

period. Experienced preceptors were seen affecting positively to learning and the transition experience. Graduates' positive experiences of the preceptor eased their transition from student to nurse, and conversely, negative experiences made transition process slower.

New graduate nurses felt 8 QARI that they were lower in the hierarchy than nurses who were permanently working in the ward. This came out for example when they were thinking of feeling of belonging and distribution of working shifts. They also felt vulnerable because of their limited experience as nurses. Nurse unit managers' attitudes were seen having a great impact on each ward's milieu and new graduate's experiences. 
Glynn and Silva, 2013, USA
To explore the expectations and experiences of new graduate nurses participating in an innovative orientation internship designed to assist in their transition to the role of the emergency nurse
8 new graduate New Graduate nurses

(completed internship programme in 2006 or 2007 instruction for 16
weeks, a nurse preceptor for 6 months
Descriptive design Structured

questionnaires and interviews

Content analysis

Departmen

Internship

Programme:

classroom
Classroom instruction, combined with clinical experiences were seen as an instructive and wellplanned start to work in the emergency department. Preceptors played an important role mostly because they were present for new graduates, worked as role models and teachers. Also the other staff was mostly supportive. Improvement ideas that newly graduated nurses brought up, were, for example, the orientation program to be longer in duration, to have more than one preceptor and to have more content on themes that they were interested in. 
Gregg et al., 2011, Japan

To report the experiences 6 nurse

6 different kind of Descriptive design of newly licensed nurses in rotational training programs lasting longer than 6 months (interviewed 6-8 rotational programs months after the rotational in 6 different

\section{Semi-structured}

interviews

training hospitals, lasting 6program started) ysed using qualitative descriptive method
Three types of experiences were found: intrapersonal,

interpersonal and systems. Rotations offered varying learning opportunities due to the possibility to visit several wards, but the newly graduated nurses experienced stress and difficulties in adapting to the environment. experienced and supportive. although, there were difficulties in integrating rotational training programs in the hospitals.

Phenomenological approach

Interviews

Analysed using

Colaizzi's method
Preceptors were

\section{QARI}

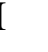

Hollywood, To explore the lived

2011, Ireland experiences of newly

stered

qualified registered

nurses $(6-18$

transition from

months of

postgraduate student

experience) support. The participants
Preceptorship was understood as getting experiences of preceptorship varied from positive experiences to not having preceptorship at all. Positive experience was, for example, a

feeling of confidence.

Results revealed that there was a lack of formal

preceptorship programmes and according to a study from 
Lea and

Cruickshank,

2005,

Australia
To ascertain if new 列 12 months rural' and if they had any of employment) regrets regarding their decision to enter a rural graduate nurse programme

Moore and Cagle, 2012 USA
To explore the phenomenon of being a new nurse in a 12- to 18 month internship programme and identify ways that CPs provide a framework during the internship experience
7 new graduate 12- or 18-month nurses (who

were participating or had participated to the internship programme) internship programme new graduate nurse's unit of 12-month graduate nurse transition program phenomenological approach

Semi-structured interviews Analysed using selective approach by van Manen
Hermeneutic-

participants, the main reason was due to staff shortage.

Participants' experiences

of new graduate programmes were negative. They felt new graduate programme advertisements differed much from reality and the promises made in advertisements were not kept. Differences occurred, for example, in ward rotations, formal orientation sessions and formal preceptorship. A good preceptor was (depending on the

Phenomenological highly valued in the method of Heidegger highly valued in the
Interviews For example, the hermeneutic preceptor's presence and approach described interest in the preceptee's employment) which by Diekelmann, learning and feelings were included 10-15 days Allen and Tanner things that had an impact of classroom learning and preceptorship with an assigned preceptor
10 QARI on the new nurse's

experiences of internship programme. The preceptor's absence, not trusting the preceptee and disrespect were some of the things that gave interns negative feelings about the internship 
programme.

Morales, 2014, To seek understanding of 7 new graduate

USA

lived experience from the nurses $(<3$

voice of Hispanic new years of

graduate nurses

\section{experience in}

professional

nursing)
Phenomenological methodology

Demographic questionnaires and in-depth, semiA Hesse-Biber and Leavy's method with four stages

\begin{tabular}{|c|c|c|}
\hline $\begin{array}{l}5 \text { new graduate } \\
\text { nurses } \\
\text { (completed the } \\
\text { new graduate } \\
\text { programme }\end{array}$ & $\begin{array}{l}12 \text {-month new } \\
\text { graduate } \\
\text { programme } \\
\text { including } 5 \text { days of } \\
\text { structured general }\end{array}$ & $\begin{array}{l}\text { Interpretive } \\
\text { paradigm } \\
\text { Semi-structured } \\
\text { interviews } \\
\text { Content analysis }\end{array}$ \\
\hline
\end{tabular}

Positive experiences with preceptors were

associated with

satisfaction in the orientation. Preceptors who had an interest in their preceptee were appreciated. Some participants felt preceptors treated them unfairly which caused negative experiences towards the preceptor and hospitals and outpatient clinics' orientation periods were found. Four themes were found: being supported, being challenged, reflections on being a new graduate and reflections on a rural new graduate program. Newly orientation. Differences in

8 QARI

between August orientation, 3 
2008 and months of rotations

December 2009) in different wards and support from Clinical Nurse

Educators

\section{Patterson et \\ al., 2013}

Canada

Spiva et al., 2013, USA
8 new graduate nurses (employed as home care nurses for 6-18 months)

21 newly

licensed

registered nurses (licensed $<12$ months)

\section{3-6-month} orientation and preceptorship program
To explore how new graduate nurses experience orientation, preceptorship and transition into independent practice in home care and how their experiences influenced their decision to remain in or leave their jobs as well as their intent to remain working in home care in the future

To describe the newly licensed registered nurse's orientation experience and to identify ways of enhancing it 
monitoring

preceptee's

orientation, for

example, to

schedule clinical

rotations, and

preceptorship improve the orientation experience. Most newly graduated nurses had positive orientation experiences. They felt supported and

encouraged. Part of the newly graduated nurses were satisfied with their preceptors knowledge, teaching and willingness to help, but also negative experiences emerged.

Some felt teaching was inconsistent and incorrect. Suggestions for improvement of the orientation program were proposed. 
Zinsmeister and Schafer, 2009, USA
To explore the lived

9 graduate

experiences of graduate nurses (worked nurses during their first 6 as staff nurses

to 12 months of 6-12 months)

employment to gain

insight into the aspects of this transition period that are particularly helpful and challenging to elicit possible methods that might improve this transition period and also increase retention rates among graduate nurses in their initial area of nursing practice employment
Phenomenological approach

Semi-structured

interviews

Content analysis
The orientation process was seen as a useful

learning process in the transition from newly graduated nurses to professional nurses. Managers helped to modify orientation to the newly graduated nurses needs. Helpful and faithful preceptors eased the orientation, transition process and raised positive experiences. 


\section{Results}

\section{Description of studies}

Of the 13 studies chosen for this systematic review, six were conducted in the USA (Delaney, 2003; Glynn and Silva, 2013; Moore and Cagle, 2012; Morales, 2014; Spiva et al., 2013; Zinsmeister and Schafer, 2009), three in Australia (Evans et al., 2008; Lea and Cruickshank, 2005; Ostini and Bonner, 2012), one in Oman (Al Awaisi et al., 2015), one in Japan (Gregg et al., 2011), one in Ireland (Hollywood, 2011) and one in Canada (Patterson et al., 2013). The number of the newly graduated nurses as participants in these studies varied from 5 to 21 newly graduated nurses and the total was 121 newly graduated nurses. The length of the orientation programmes varied from 12 weeks to 18 months. In three studies (Hollywood, 2011; Morales, 2014; Zinsmeister and Schafer, 2009), the orientation programme was not described.

\section{Orientation experiences of newly graduated nurses}

As a result of the content analysis, newly graduated nurses' orientation experiences were divided into four main categories: experiences related to the orientation arrangements; experiences related to the preceptor; experiencing role transition during the orientation; and suggestions for changes based on the orientation experiences (Figure 2). 
Subcategories
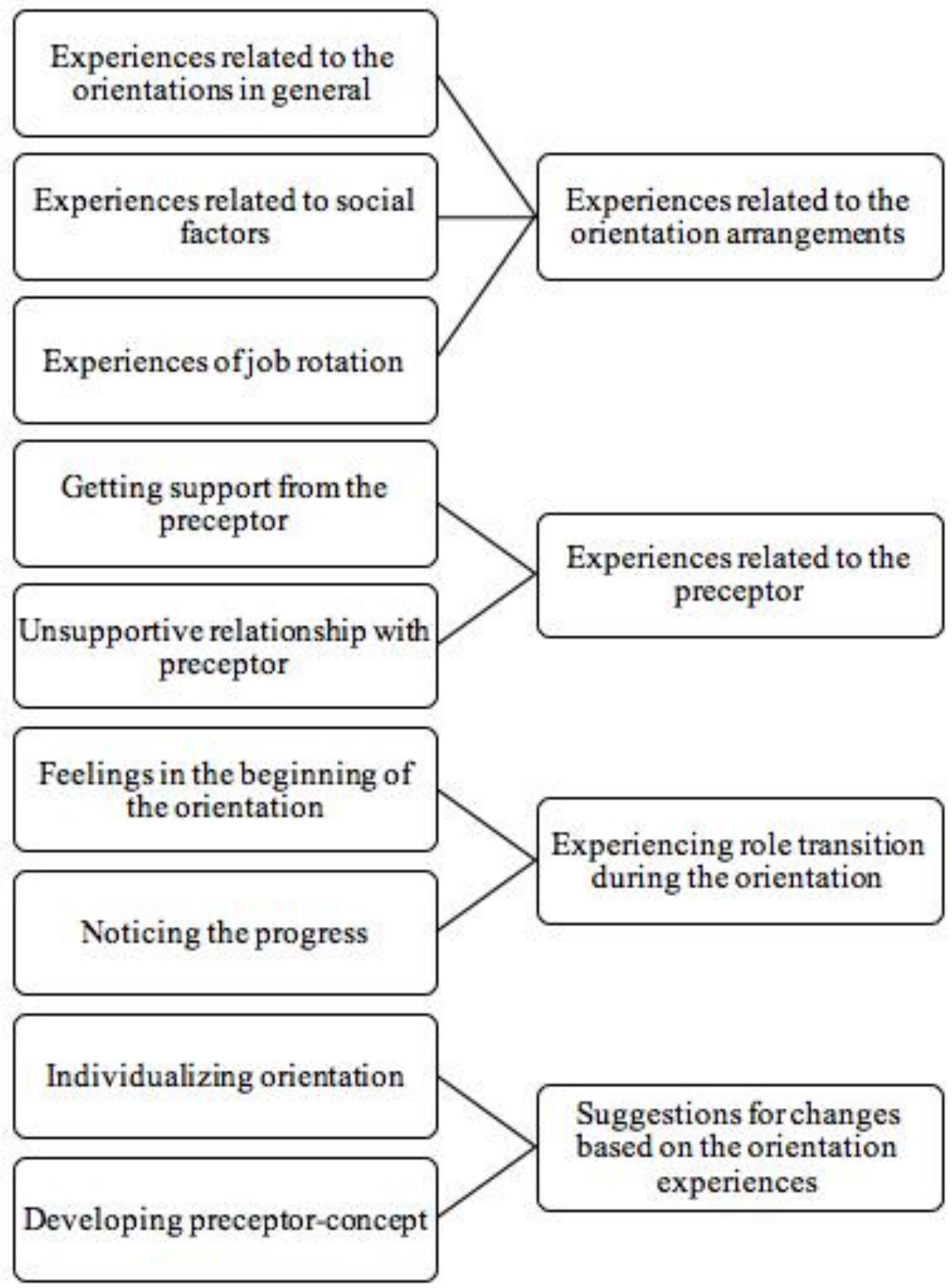

Figure 2. Main and subcategories of newly graduated nurses' orientation experiences.

\section{Experiences related to the orientation arrangements}

Experiences related to the orientation arrangements were separated into three subcategories.

Subcategories were experiences related to the orientations in general, experiences related to social factors and experiences of job rotation. 
Experiences related to the orientations in general

Generally, the orientation programmes were appraised to be an important and positive experience (Al Awaisi et al., 2015; Glynn and Silva, 2013) and newly graduated nurses felt welcomed and supported (Delaney 2003; Spiva et al., 2013). The structure of the orientation was assessed as good and newly graduated nurses appreciated the balance between the classroom teaching and the clinical training (Glynn and Silva, 2013). Most of the preceptees felt that the orientation was long enough and they were ready to work independently after that (Delaney, 2003; Glynn and Silva, 2013). It was evaluated that getting familiar with the unit took about three weeks and with the transitional programme and the concept of being a qualified nurse about three to six months (Ostini and Bonner, 2012). However, there was also dissatisfaction and disappointments related to the orientation programmes (Evans et al., 2008; Glynn and Silva, 2013; Hollywood, 2011; Lea and Cruickshank, 2005; Moore and Cagle, 2012; Ostini and Bonner, 2012) and some would have liked the orientation to be a bit longer (Delaney, 2003; Glynn and Silva, 2013).

Differences between orientations in hospitals and outpatient clinics were remarked on (Morales 2014; Ostini and Bonner, 2012). Not all the outpatient clinics offered the orientation programme they promised (Lea and Cruickshank, 2005) and there was not, for example, a possibility to have a preceptor (Lea and Cruickshank, 2005; Morales 2014), the orientation was shorter than the one hospitals provided (Morales 2014), preceptees did not get feedback and the rotations promised did not exist (Lea and Cruickshank, 2005). Also, the introductions given to the orientation in larger agencies did not match the reality in smaller clinics and these negative aspects could lead to exiting the orientation programme (Lea and Cruickshank, 2005). This being said, outpatient clinics were experienced to have some other advantages compared to the hospital environment (Morales 2014; Ostini and Bonner, 2012), for example, different kinds of independency and co-operation with other personnel (Morales 2014), friendly staff and patients, variation in learning opportunities, and better chances of employment after the orientation programme (Ostini and Bonner, 2012). Newly graduated nurses felt that the orientation in outpatient clinics was less stressful and concerns related to the acceptance of multiculturality were unnecessary (Ostini and Bonner, 2012).

\section{Experiences related to social factors}

Staff on the wards were experienced as supportive (Glynn and Silva, 2013; Gregg et al., 2011; Ostini and Bonner, 2012; Spiva et al., 2013) and relationships with them and clients were seen as an important part of creating confidence and passion for nursing (Patterson et al., 2013). Also, help from clinical educators was appreciated (Glynn and Silva, 2013; Ostini and Bonner, 2012). Getting to share experiences with other newly graduated nurses helped to reveal stress (Gregg et al., 2011).

Besides the good experiences of staff, some felt confusion when working with others than their preceptor (Glynn and Silva, 2013; Ostini and Bonner, 2012) and some thought staff expected more skills than newly graduated nurses had (Ostini and Bonner, 2012). Experiences of bullying (Evans et al., 2008; Glynn and Silva, 2013; Moore and Cagle, 2012), not feeling a part of the permanent staff and being unfairly treated with shifts (Evans et al., 2008) did occur. At some wards, priority was noticed given to the nurses that had been working longer on the ward (Gregg et al., 2011). Nurse managers were recognised to sometimes influence the ward milieu negatively, which also had an effect on meeting the newly graduated nurses either (Evans et al., 2008). Not all the newly graduated nurses received support from the clinical educators (Ostini and Bonner, 2012). The orientation programmes were recognised to be answering the staffing requirements and programmes' amount of available positions to be linked to it (Evans et al., 2008). 


\section{Experiences of job rotation}

Newly graduated nurses had a lot of positive experiences connected to the rotation periods on different wards during their orientation (Glynn and Silva, 2013; Gregg et al., 2011; Ostini and Bonner, 2012). Rotations were experienced as supportive (Ostini and Bonner, 2012), increasing opportunities to learn from different health conditions on different wards (Gregg et al., 2011). Rotations were noticed to create a possibility to get to know many people and even help newly graduated nurses to find pleasing employment (Gregg et al., 2011). During rotations, preceptees were allowed to observe and had fewer patients, which was marked to enrich learning (Gregg et al., 2011). Newly graduated nurses felt regret if they did not participate some rotations (Glynn and Silva, 2013; Ostini and Bonner, 2012) if, for example, the thought of rotating to a certain unit felt too difficult (Ostini and Bonner, 2012).

Still, some negative aspects related to rotations also came out (Glynn and Silva, 2013; Gregg et al., 2011). There was variation in the rotational training programmes in different rotation units and it seemed that not all the staff were familiar with or prepared for the rotational training programmes, there was no preceptor offered in all the units, and also other teaching methods varied (Gregg et al., 2011). Preceptees felt a lack of fellowship (Gregg et al., 2011), and had difficulties in bonding with patients (Glynn and Silva, 2013), getting the feeling of working as an independent nurse and adapting to the environment (Gregg et al., 2011) because of such a short time in the unit. Rotations made newly graduated nurses feel greater stress. The broad learning experiences, that the rotations offered, were seen negatively because of learning was felt to remain superficial. (Gregg et al., 2011.)

\section{Experiences related to the preceptor}

Experiences related to the preceptor were separated into two subcategories. Subcategories were getting support from the preceptor and unsupportive relationship with preceptor.

\section{Getting support from the preceptor}

Many of the newly graduated nurses felt that they got support from their preceptor (Glynn and Silva, 2013; Gregg et al., 2011; Hollywood, 2011; Moore and Cagle, 2012; Morales, 2014; Patterson et al., 2013). Some even saw that the preceptor was the most important actor in their orientation process (Glynn and Silva, 2013; Moore and Cagle, 2012). At best, preceptors created a nurturing and supportive environment for learning (Glynn and Silva, 2013; Patterson et al., 2013; Spiva et al., 2013). A positive relationship with the preceptor was seen to have an impact on creating a positive experience of the whole transition (Delaney, 2003; Glynn and Silva, 2013; Zinsmeister and Schafer, 2009) and orientation process (Morales, 2014), and helping to progress in orientation (Delaney, 2003; Spiva et al., 2013; Zinsmeister and Schafer, 2009). Some newly graduated nurses preferred one preceptor for the entire orientation while some thought more than one preceptor brought good variation to learning (Glynn and Silva, 2013).

Newly graduated nurses experienced learning a lot of new practical skills from preceptors (Glynn and Silva, 2013; Hollywood, 2011; Moore and Cagle, 2012; Patterson et al., 2013; Spiva et al., 2013). These were for example separating work from home (Glynn and Silva, 2013; Moore and Cagle, 2012), clinical skills (Glynn and Silva, 2013; Spiva et al., 2013), communicating with patients (Glynn and Silva, 2013) and time management (Moore and Cagle, 2012). Good preceptors acted as role models to newly graduated nurses (Glynn and Silva, 2013), encouraged to think and work independently (Moore and Cagle, 2012; Patterson et al., 2013), acted fairly (Glynn and Silva, 2013; Spiva et al., 2013), were seasoned, knowledgeable (Spiva et al., 2013) and present (Moore and Cagle, 2012). Newly graduated nurses felt that the preceptor was a person to whom they were 
able to tell their worries and troubles (Gregg et al., 2011). It was described as a positive experience if the preceptor wanted to stay in contact after the orientation (Spiva et al., 2013). Through these new learning experiences and preceptor's support, newly graduated nurses felt their confidence increased (Hollywood, 2011; Moore and Cagle, 2012; Patterson et al., 2013; Spiva et al., 2013).

\section{Unsupportive relationship with preceptor}

Also negative experiences towards preceptors transpired (Al Awaisi et al., 2015; Delaney, 2003; Hollywood, 2011; Moore and Cagle, 2012; Morales, 2014; Ostini and Bonner, 2012; Patterson et al., 2013; Spiva et al., 2013). Like positive experiences but conversely, negative experiences were seen to have an impact on orientation progress by delaying it (Delaney, 2003) and even by getting newly graduated nurses to seek other employment (Patterson et al., 2013). In some cases, there was no organised, formal working with preceptors and the term preceptor was mixed with the term mentorship (Hollywood, 2011). Newly graduated nurses felt that some preceptors were not prepared for role modelling (Al Awaisi et al., 2015), and there was a lack of time (Al Awaisi et al., 2015; Patterson et al., 2013), the preceptor's presence (Moore and Cagle, 2012) and knowledge (Delaney, 2003; Spiva et al., 2013). Preceptor's or preceptors' teaching was experienced inconsistent (Al Awaisi et al., 2015; Delaney, 2003; Spiva et al., 2013), unfair (Morales, 2014; Spiva et al., 2013), and newly graduated nurses were afraid of communicating with them (Spiva et al., 2013).

\section{Experiencing role transition during the orientation}

Experiencing role transition during the orientation was separated into two subcategories.

Subcategories were feelings at the beginning of the orientation; and noticing the progress.

\section{Feelings in the beginning of the orientation}

After their graduation and in the beginning the orientation, newly graduated nurses felt stressed (Delaney, 2003), insecure (Al Awaisi et al., 2015; Ostini and Bonner, 2012; Spiva et al., 2013), inexperienced (Al Awaisi et al., 2015) and incompetent to work independently (Al Awaisi et al., 2015; Spiva et al., 2013). They were experiencing dissatisfaction with their education for preparing them poorly into the practice (Evans et al., 2008). Responsibility and rotational changes caused them stress, but they also saw them as providing varying learning opportunities (Ostini and Bonner, 2012). Newly graduated nurses thought that learning new skills was necessary (Glynn and Silva, 2013) and that there were difficulties, for example, in time management (Al Awaisi et al., 2015), but sometimes the learning situations felt so scary that they decided not to attend them (Ostini and Bonner, 2012).

\section{Noticing the progress}

During and after orientation, newly graduated nurses noticed their process from having no responsibilities to fully independent staff nurse (Al Awaisi et al., 2015), felt their confidence had increased (Delaney, 2003; Ostini and Bonner, 2012) and that they had more competencies permitting them to work independently (Glynn and Silva, 2013; Ostini and Bonner, 2012). Newly graduated nurses experienced orientation had influenced positively to their role transition process (Zinsmeister and Schafer, 2009) and helped them with learning new skills (Glynn and Silva, 2013; Ostini and Bonner, 2012; Spiva et al., 2013) and implementing theoretical skills in practice (Ostini and Bonner, 2012), which also caused confusion (Al Awaisi et al., 2015). In practical abilities, like time management, communication (Spiva et al., 2013), coping with and managing unfamiliar situations (Ostini and Bonner, 2012), and providing safe nursing care (Glynn and Silva, 2013), progress was recognised. During orientation, rotations were felt to become easier (Ostini and Bonner, 2012) and newly graduated nurses started to feel a sense of belonging to the unit (Delaney, 
2003). The transition process as a whole was seen as an outcome (Glynn and Silva, 2013), challenging, but also offering a rewarding learning opportunity (Delaney, 2003; Ostini and Bonner, 2012), and seeing progress happen gave comfort and strength (Delaney, 2003).

\section{Suggestions for changes based on orientation experiences}

Newly graduated nurses' suggestions for changes based on the orientation experiences were separated into two subcategories. Subcategories were: individualising orientation and developing preceptor-concept.

\section{Individualising orientation}

Newly graduated nurses saw that individualising the orientation period to better respond to the preceptee's individual needs, would bring advantages (Spiva et al., 2013). Individualising was proposed to happen, for example, by adding (Ostini and Bonner, 2012; Spiva et al., 2013) and restructuring (Spiva et al., 2013) study days, implementing computer-based learning to orientation (Spiva et al., 2013), and adding more content of different topics (Glynn and Silva, 2013). Individualising related to the rotations was proposed to happen by adding rotations if those did not already exist (Glynn and Silva, 2013), add longer and more challenging rotations and change the order of rotations (Ostini and Bonner, 2012). Yet, some suggested that not changing the orientation unit during the orientation would serve them better (Spiva et al., 2013). Newly graduated nurses wished more consistent and timely feedback (Spiva et al., 2013) and increased access to the nurse educators (Ostini and Bonner, 2012).

\section{Developing preceptor-concept}

Newly graduated nurses suggested working with preceptors to be developed to follow a formal, common programme (Spiva et al., 2013). Some wished to have more than one preceptor to see more variation in working styles (Glynn and Silva, 2013). Newly graduated nurses were of the opinion that developing their relationship with their preceptor after the orientation period, in the form of mentorship, for example, would be useful (Spiva et al., 2013) as would also networking through nursing associations (Morales, 2014).

\section{Discussion}

A systematic review was conducted to reach the aim of this review, which was to describe newly graduated nurses' experiences related to the orientation in nursing. Four main categories, experiences related to the orientation arrangements; experiences related to the preceptor; experiencing role transition during the orientation; and suggestions for changes based on the orientation experiences, were created to explain this phenomenon as it was portrayed by newly graduated nurses in those thirteen studies selected to this review.

The results highlighted the momentous influence of the orientation and the preceptor on the newly graduated nurses' experiences of the start of their career (Delaney, 2003; Glynn and Silva, 2013; Moore and Cagle, 2012; Morales, 2014; Zinsmeister and Schafer, 2009). At best, orientation prepared preceptees for practice (Delaney, 2003; Glynn and Silva, 2013) and the preceptor had an impact on creating a positive picture of the transition process as whole (Delaney, 2003; Glynn and Silva, 2013; Zinsmeister and Schafer, 2009). On the other hand, at worst, the dissatisfaction with the rotations during the orientation (Lea and Cruickshank, 2005) and the preceptor (Patterson et al., 2013) was related to the cause why newly graduated nurse exited their jobs. In addition to the influence on newly graduated nurses' experiences that these results demonstrate, they also compel to pay attention to the variation and imbalance in the orientation programmes' and preceptors' 
quality. The variation of the quality sets newly graduated nurses in an unequal position, which is not salutary for either the newly graduated nurse or the employer. It is also unfair, unreasonable and extremely stressful for the preceptors to act as a preceptor without any employer investment in preceptor training or time for preceptorship. Based on these results and also the results from other studies (Flinkman et al., 2013), it seems that there is a serious lack of orientation and support at least in some workplaces, and therefore it would be necessary to research more widely the situation of the orientation both from the employers' and the employees' perspectives.

Duchscher (2008) describes the stages of transition. At the first stage, most of the newly graduated nurses had idealistic expectations of their upcoming job, and then were disappointed for example because of the large workload. Also according to the results of this study, the beginning of the orientation and the newly graduated nurses' career is very stressful (Delaney, 2003) and insecure (Al Awaisi et al., 2015; Ostini and Bonner, 2012; Spiva et al., 2013). As in every period of the career, at this very early stage too, they experienced bullying (Evans et al., 2008; Glynn and Silva, 2013; Moore and Cagle, 2012). Unprofessional behaviour arose also from other studies, where newly graduated nurses faced inappropriate criticism and insolence (Pellico et al., 2009). Newly graduated nurses are often easy targets. The negative experiences can be so heavy that they may even result in quitting. (Pellico et al., 2009)

Something that is also wanted to point out from the results is that the newly graduated nurses' wish to continue the relationship with their preceptor after the orientation period, for example, in the form of mentorship (Spiva et al., 2013). This is congruous with the results of the systematic review researching mentoring programmes' benefits for newly graduated nurses, which presents mentoring's advantages related to, for example, turnover rate, cost effectiveness, job satisfaction and nursing competence (Zhang et al., 2016). Mentorship is an issue that is needed to raise in discussion and develop further as a more formal entirety. The need to individualise the orientation to meet preceptees' demands was also expressed in Tastan's et al. (2013) study.

During this qualitative research process, it was noted that ten studies were needed to leave out from the review because of their low scores in quality assessment. Most of the studies had shortcomings in the methodological parts of the report. This was, for a large part, a pity, because some studies that would otherwise have been good to select for this review were missed. In the future, authors should pay attention to the quality of their studies more carefully.

\section{Limitations}

PRISMA 2009 Checklist (Moher et al., 2009) was used to evaluate the methodological quality of this review. To fulfil the reliability requirements of the qualitative research (Polit and Beck, 2014), we paid attention in particular to the limitations related to reporting as we reviewed the methodological quality of this review (Higgins and Green, 2011). Language limitations (Higgins and Green, 2011) was reduced by avoiding language limitations when data was searched. Only one Chinese study was removed after the screening of abstracts. We endeavoured to search data extensively with the aid of an information specialist. Still, we might have missed some search terms and databases that might have been crucial to the aim of the review. Publication and outcome reporting limitations were avoided by describing the results as objectively, clearly and honestly as the researcher could (Higgins and Green, 2011), but despite all this, inevitably the analysis is the result of the work made by two researchers with personal opinions and a certain concept. By reporting the time frame for data searches, we sought to minimise time lag and multiple publication limitations by reporting all the results in the same publication (Higgins and Green, 2011). Through 
the research process, researchers were aware of different types of research misconduct and the review was performed by following good ethical principles (Polit and Beck, 2012).

\section{Conclusions}

A lot of studies (Jones et al., 2014; Owens, 2013; Thabault et al., 2015) have been done to support the early years of the newly graduated nurses' career. This systematic review of newly graduated nurses' experiences related to the orientation highlighted that the orientation programmes and the preceptors have a significant impact on the newly graduated nurses' transition process from student to newly qualified nurse and that there is a wide variation of the orientation programmes in different health care units. These results join together and emphasise the positive and negative aspects that newly graduated nurses relate to the current orientation programmes and thereby provide avail to the development of the orientation programmes.

\section{Acknowledgments}

We would like to thank the information specialist Sirpa Grekula from the University of Oulu for giving such enriching guidance.

\section{References}

Al Awaisi, H., Cooke, H., Pryjmachuk, S., 2015. The experiences of newly graduated nurses during their first year of practice in the Sultanate of Oman - A case study. International Journal of Nursing Studies 52 (11), 1723-1734, http://dx.doi.org/10.1016/j.ijnurstu.2015.06.009.

AL-Dossary, R., Kitsantas, P., Maddox, P.J., 2014. The impact of residency programs on new nurse graduates' clinical decision-making and leadership skills: A systematic review. Nurse Education Today 34 (6), 1024-1028, http://dx.doi.org/10.1016/j.nedt.2013.10.006.

Beecroft., P.C., Kunzman, L., Krozek, C., 2001. RN Internship Outcomes of a One-Year Pilot Program. Journal of Nursing Administration 31 (12), 575-582.

Benner, P., 1984. From novice to expert: Excellence and power in clinical nursing practice. Addison-Wesley, Menlo Park, pp. 13-34.

Centre for Reviews and Dissemination (CRD), 2009. Systematic Reviews: CRD's guidance for undertaking reviews in health care. University of York, CRD.

Delaney, C., 2003. Walking the Fine Line: Graduate Nurses' Transition Experiences During Orientation. Journal of Nursing Education 42 (10), 437-443.

Duchscher, J.B., 2008. A Process of Becoming: The Stages of New Nursing Graduate Professional Role Transition. The Journal of Continuing Education in Nursing 39 (10), 441-450.

Elo, S., Kyngäs, H., 2008. The qualitative content analysis process. Journal of Advanced Nursing 62 (1), 107-115, http://dx.doi.org/10.1111/j.1365-2648.2007.04569.x.

Evans, J., Boxer, E., Sanber, S., 2008. The strengths and weaknesses of transitional support programs for newly registered nurses. Aurstralian Journal of Advanced Nursing 25 (4), 16-22.

Firtko, A., Stewart, R., Knox, N., 2005. Understanding mentoring and preceptorship: Clarifying the quagmire. Contemporary Nurse 19 (1-2), 32-40.

Flinkman, M., Isopahkala-Bouret, U., Salanterä, S., 2013. Young Registered Nurses' Intention to Leave the Profession and Professional Turnover in Early Career: A Qualitative Case Study. ISRN Nursing, 916061, http://dx.doi.org/10.1155/2013/916061.

Flinkman, M., Laine, M., Leino-Kilpi, H., Hasselhorn, H.M., Salanterä, S., 2008. Explaining young registered Finnish nurses' intention to leave the profession: A questionnaire survey.

International Journal of Nursing Studies 45 (5), 727-739, http://dx.doi.org/10.1016/j.ijnurstu.2006.12.006. 
Glynn, P., Silva, S., 2013. Meeting the needs of new graduated in the emergency department: A qualitative study evaluating a new graduate internship program. Journal of Emergency Nursing 39 (2), 173-178, http://dx.doi.org/10.1016/j.jen.2011.10.007.

Goh, Y.S., Lee, A., Chan, S.W.C., Chan, M.F., 2015. Profiling nurses' job satisfaction, acculturation, work environment, stress, cultural values and coping abilities: A cluster analysis. International Journal of Nursing Practice 21 (4), 443-452, http://dx.doi.org/10.1111/ijn.12318.

Gregg, M.F., Shigematsu, T., Hayashi, C., Kono, M., Yoshida, K., 2011. Newly Licenced Nurses' Experiences in Rotational Training Programs in Japan. The Journal of Continuing Education in Nursing 42 (2), 89-96, http://dx.doi.org/10.3928/00220124-20101101-03.

Higgins, J.P.T., Green, S. (Eds.), 2011. Cochrane Handbook for Systematic Reviews of Interventions Version 5.1.0. The Cochrane Collaboration, http://www.handbook.cochrane.org (accessed 21.06.16).

Higgins, G., Spencer, R.L., Kane, R., 2010. A systematic review of the experiences and perceptions of the newly qualified nurse in the United Kingdom. Nurse Education Today 30 (6), 499-508, http://dx.doi.org/10.1016/j.nedt.2009.10.017.

Hollywood, E., 2011. The lived experiences of newly qualified children's nurses. British Journal of Nursing 20 (11), 661-671.

Joanna Briggs Institute (JBI), 2014. Joanna Briggs Institute Reviewers’ Manual (2014 ed.) University of Adelaide, The Joanna Briggs Institute.

Jones, A., Benbow, J., Gidman, R., 2014. Provision of training and support for newly qualified nurses. Nursing Standard 28 (19), 44-50, http://dx.doi.org/10.7748/ns2014.01.28.19.44.e8191.

Laschinger, H.K.S., 2012. Job and career satisfaction and turnover intentions of newly graduated nurses. Journal of Nursing Management 20 (4), 472-484, http://dx.doi.org/10.1111/j.13652834.2011.01293.x.

Lea, J., Cruickshank, M., 2005. Factors that influence the recruitment and retention of graduate nurses in rural health care facilities. Collegian 12 (2), 22-27.

Lin, P.S., Viscardi, M.K., McHugh, M.D., 2014. Factors Influencing Job Satisfaction of New Graduate Nurses Participating in Nurse Residency Programs: A Systematic Review. Journal of Continuing Education 45 (10), 439-450, http://dx.doi.org/10.3928/00220124-20140925-15.

Lofmark, A., Smide, B., Wikblad, K., 2006. Competence of newly-graduated nurses - a comparison of the perceptions of qualified nurses and students. Journal of Advanced Nursing 53 (6), 721 728.

Malouf, N., West, S., 2011. Fitting in: A pervasive new graduate nurse need. Nurse Education Today 31 (5), 488-493, http://dx.doi.org/10.1016/j.nedt.2010.10.002.

Missen, K., McKenna, L., Beauchamp, A., 2014. Satisfaction of newly graduated nurses enrolled in transition-to-practice programmes in their first year of employment: a systematic review. Journal of Advanced Nursing 70 (11), 2419-2433, http://dx.doi.org/10.1111/jan.12464.

Moher, D., Liberati, A., Tetzlaff, J., Altman, D.G., 2009. Preferred Reporting Items for Systematic Reviews and Meta-Analyses: The PRISMA Statement. PLoS Med 6 (7), e1000097, http://dx.doi.org/10.1371/journal.pmed.1000097.

Moore, P., Cagle, C.S., 2012. The Lived Experiences of New Nurses: Importance of the Clinical Preceptor. The Journal of Continuing Education in Nursing 43 (12), 555-565, http://dx.doi.org/10.3928/00220124-20120904-29.

Morales, E.G., 2014. Lived experiences of Hispanic new graduate nurses - a qualitative study. Journal of Clinical Nursing 23 (9-10), 1292-1299, http://dx.doi.org/10.1111/jocn.12339.

Myrick, F., Yonge, O., 2002. Preceptor Behaviors Integral to the Promotion of Student Critical Thinking. Journal for Nurses in Staff Development 18 (3), 127-133.

Oxford Dictionary of English, 2016. Electronic dictionary. http://www.oxforddictionaries.com/definition/english/orientation (accessed 22.06.16). 
Ostini, F., Bonner, A., 2012. Australian new graduate experiences during their transition program in a rural/regional acute care setting. Contemporary Nurse 41 (2), 242-252, http://dx.doi.org/10.5172/conu.2012.41.2.242.

Owens, N.G., 2013. New graduate nurse preceptor program: A collaborative approach with academia. Journal of Nursing Education and Practice 3 (12), 1-9, http://dx.doi.org/10.5430/jnep.v3n12p1.

Park, M., Jones, C.B., 2010. A Retention Strategy for Newly Graduated Nurses. An Integrative Review of Orientation Programs. Journal for Nurses in Staff Development 26 (4), 142-149, http://dx.doi.org/10.1097/NND.0b013e31819aa130.

Patterson, E., Hart, C., Bishop, S.E., Purdy, N., 2013. Deciding if Home Care Is Right for Me: The Experience of the New Graduate Nurse. Home Health Care Management \& Practice 25 (4), 147-154, http://dx.doi.org/10.1177/1084822312473828.

Pellico, L.H., Brewer, C.S., Kovner, C.T., 2009. What newly licensed registered nurses have to say about their first experiences. Nursing Outlook 57 (4), 194-203, http://dx.doi.org/10.1016/j.outlook.2008.09.008.

Polit, D.F., Beck, C.T., 2012. Nursing Research: Generating and Assessing Evidence for Nursing Practice. Lippincott Williams \& Wilkins, Philadelphia.

Polit, D.F., Beck, C.T., 2014. Essentials of Nursing Research: Appraising Evidence for Nursing Practice. Lippincottt Williams \& Wilkins, Philadelphia.

Rudman, A., Gustavsson, J.P., 2011. Early-career burnout among new graduate nurses: A prospective observational study of intra-individual change trajectories. International Journal of Nursing Studies 48 (3), 292-306, http://dx.doi.org/10.1016/j.ijnurstu.2010.07.012.

Rudman, A., Gustavsson, J.P., Hultell, D., 2014. A prospective study of nurses' intentions to leave the profession during their first five years of practice in Sweden. International Journal of Nursing Studies 51 (4), 612-624, http://dx.doi.org/10.1016/j.ijnurstu.2013.09.012.

Rudman, A., Omne-Pontén, M., Wallin, L., Gustavsson, P.J., 2010. Monitoring the newly qualified nurses in Sweden: the Longitudinal Analysis of Nursing Education (LANE) study. Human Resources for Health 8:10, http://dx.doi.org/10.1186/1478-4491-8-10.

Rush, K.L., Adamack, M., Gordon, J., Janke, R., Ghement, I.R., 2015. Orientation and transition programme component predictors of new graduate workplace integration. Journal of Nursing Management 23 (2), 143-155. http://dx.doi.org/10.1111/jonm.12106.

Rush, K.L., Adamack, M., Gordon, J., Lilly, M., Janke, R., 2013. Best practices of formal new graduate nurse transition programs: An integrative review. International Journal of Nursing Studies 50 (3), 345-356, http://dx.doi.org/10.1016/j.ijnurstu.2012.06.009.

Salminen, H., 2012. Turning the tide: Registered nurses' job withdrawal intentions in a Finnish university hospital. SA Journal of Human Resource Management 10 (2), http://dx.doi.org/10.4102/ sajhrm.v10i2.410.

Scott, E.S., Engelke, M.K., Swanson, M., 2008. New graduate nurse transitioning: Necessary or nice? Applied Nursing Research 21 (2), 75-83, http://dx.doi.org/10.1016/j.apnr.2006.12.002.

Sermeus, W., Bruyneel, L., 2010. Investing in Europe's health workforce of tomorrow: Scope for innovation and collaboration. Summary report of the three Policy Dialogues. https://www.enpam.it/wp-content/uploads/Report-PD-Leuven-FINAL.pdf (accessed 21.06.16).

Spiva, L., Hart, P.L., Pruner, L., Johnson, D., Martin, K., Brakovich, B., McVay, F., Mendoza, S.G., 2013. Hearing the Voices of Newly Licenced RNs: The Transition to Practice. American Journal of Nursing 113 (11), 24-32, http://dx.doi.org/10.1097/01.NAJ.0000437108.76232.20.

Tastan, S., Unver, V., Hatipoglu, S., 2013. An analysis of the factors affecting the transition period to professional roles for newly graduated nurses in Turkey. International Nursing Review 60 (3), 405-412, http://dx.doi.org/10.1111/inr.12026. 
Thabault, P., Mylott, L., Patterson, A., 2015. Describing a Residency Program Developed for Newly Graduated Nurse Practitioners Employed in Retail Health Settings. Journal of Professional Nursing 31 (3), 226-232, http://dx.doi.org/10.1016/j.profnurs.2014.09.004.

Whitehead, B., Holmes, D., 2011. Are newly qualified nurses prepared for practice? Nursing Times 107 (19-20), 20-23.

Yeh, M., Yu, S., 2009. Job stress and intention to quit in newly-graduated nurses during the first three months of work in Taiwan. Journal of Clinical Nursing 18 (24), 3450-3460, http://dx.doi.org/10.1111/j.1365-2702.2009.02941.x.

Zhang, Y., Qian, Y., Wu, J., Wen, F., Zhang, Y., 2016. The effectiveness and implementation of mentoring program for newly graduated nurses: A systematic review. Nurse Education Today 37 (2), 136-144, http://dx.doi.org/10.1016/j.nedt.2015.11.027.

Zinsmeister, L.B., Schafer, D., 2009. The Exploration of the Lived Experience of the Graduate Nurse Making the Transition to Registered Nurse During the First Year of Practice. Journal for Nurses in Staff Development 25 (1), 28-34, http://dx.doi.org/10.1097/NND.0b013e318194b58c. 